Research Laboratories, Washington, D.C.), discussed the deductions to be made concerning the nature of emission centres from such physical measurements as dependence of efficiency, phosphorescence decay and absorption and emission spectra on temperature, characteristics of sensitization and concentration quenching. The paper by Dr. G. R. Fonda (General Electric Co., Schenectady), which followed, considered energy transfer between activators in calcium halophosphate phosphors. A paper by Dr. C. C. Klick (Naval Research Laboratories, Washington, D.C.) brought to the fore the particular case of divalent manganese as a luminescence activator in solids. Both the paper and subsequent discussions showed clearly the divergence of opinions on the relations between spectral characteristics of luminescence and the state of the manganese ion, that is, whether spectral changes are due to association and clustering of impurities or to changes in co-ordination of the impurity with its surroundings. The idea of pairing of impurities was emphasized in more detail for specific cases, such as alkaline earth oxides, uranate and fluoride phosphors, in a theoretical paper by Mr. W. A. Runciman (General Electric Laboratories, Wembley).

The last session of the conference dealt with fundamental mechanisms of luminescence in solids and opened with a paper by Dr. G. F. J. Garlick (University of Birmingham) on absorption, emission and storage processes in sulphide phosphors. There followed a theoretical paper by Dr. I. Broser and Dr. R. Broser-Warminsky (Berlin) on the correlation of luminescence and photoconduction characteristics with energy-states of single-crystal phosphors. These authors also presented new experimental results on thermoluminescence and dark current against temperature variations in single sulphide crystals. These papers and the discussions on them emphasized the difficulty of determining the energy distribution of trapping-states in phosphors by the sole use of thermal glow experiments. Contributions from members of the Eindhoven group indicated some new mothods of detecting trapping-states not operative in thermoluminescence. Control and analysis of phosphors for such experiments is essential, and the use of radioactive isotopes of constituent elements for this purpose was described in a contribution by Dr. E. and Mme. B. Grillot, (Paris).

The progress made in recent years in the theory of localized activator centres in phosphors, particularly for impurities such as thallous and manganous ions in ionic solids, was described by Dr. F. E. Williams (General Electric Co., Schenectady). An important feature of the paper was the extension of the theoretical methods to covalent crystals such as zinc and cadmium sulphides activated by copper which are usually treated on the basis of the energyband model. The next paper, by Dr. G. F. J. Garlick (University of Birmingham), attempted to lay a sound foundation for a quantitative theoretical treatment of cathodoluminescence. The final paper, by Dr. C. A. Duboc (Eastman-Kodak Co., Rochester, United States), discussed non-linear relations between fluorescence and excitation density in photoconducting phosphors, a subject of much interest in recent years. Exhaustive analysis was made of the possible energy-level schemes giving rise to non-linearity effects.

Discussions on the papers of this session were lively, probably because experimental investigations do not yet yield results which can distinguish between the various theoretical approaches and models.

The general impression given by the proceedings was that phosphor research is becoming more exact and more closely related to other fields of solid-state physics-for example, to semi-and photo-conduction. There was even mention of a possible role for dislocations in the formation of some types of emission centre. It was further evident that, although powderform phosphors are still the most important materials for commercial use, precise fundamental investigations demand that the specimens shall be in singlecrystal form.

G. F. J. GARLICK

\section{ATMOSPHERIC CONTAMINATION IN INDUSTRY AND THE HEALTH OF THE WORKER}

$\mathrm{O}^{\mathrm{N}}$ April 6 the British Occupational Hygiene Society held a conference at the London School of Hygiene and Tropical Medicine, which was devoted to the discussion of problems of atmospheric contamination in industry and its effects on the health of workers. The conference was attended by a hundred and fifty members and visitors. Copies of the proceedings will be available from the honorary secretary, Mr. Peter C. G. Isaac, Public Health Engineering Laboratory, King's College, Newcastle upon Tyne.

The first paper, "The Investigation of Atmospheric Contaminants in Factories", was presented by two authors, Dr. M. W. Goldblatt, head of the Industrial Hygiene Laboratories, Imperial Chemical Industries, Ltd., and Dr. J. C. Gage, head of the Biochemical Section of these Laboratories. In dealing with the fundamental aspects, Dr. Goldblatt suggested that the present standards of medical supervision of workers have to be considered as minimal. While it is true that big organizations have safety and medical departments, the workers and managements of the 230,000 small factories that have less than $100 \mathrm{em}$ ployees have little contact with the medical profession. Although the number of notified cases of industrial poisoning is very small, this gives a false impression, and it is probable that the absorption of toxic materials is widespread in industry. It is possible that, with modern medical diagnosis and treatment, men suffering from mild, chronic poisoning can be kept at work. Dr. Goldblatt said that it is important that where toxic materials may be absorbed by the workpeople, their concentration in the air should be determined. It is also important to keep adequate records so that, over a period of time, it may be possible to correlate the clinical histories and the concentration of toxic materials in the atmosphere. The concept of 'maximum allowable concentration' has come into fairly common use, but Dr. Goldblatt suggested that 'allowable' concentrations always have to be zero. He agreed that in practice it is necessary to accept a 'design' concentration which may be used by the engineer designing the equipment as a criterion for the efficiency of any control system. This design concentration should be such that the health of the exposed workers is not affected over a prolonged period of time. He warned his audience against the wrong use of the published tables of 'maximum allowable concentrations'. In particular, it is mis- 
leading to compare materials having different effects. It is also most dangerous to predict the toxicity of the materials by chemical analogy.

In presenting the second section of the paper, Dr. Gage pointed out that, unlike studies of atmospheric pollution in towns, the nature of the hazardous material is usually known within the factory. $\mathrm{H}_{\theta}$ stated that the requirements of a method for general use in a factory are that it should be unobtrusive, inexpensive and self-contained; it should give an immediate result and be sufficiontly simple to be used by a laboratory assistant or foreman. Also, it has to be adequately accurate and specific. Sampling equipment of this type is particularly suitable for the testing of air purity before men are permitted to enter a tank or enclosed space. Dr. Gage outlined the main types of methods available and gave a demonstration of an indicator tube for carbon monoxide; this is a very simple procedure which he thinks should be extended to other gases. Reference was made to more complex instrumental methods - for example, the mercury vapour detector using ultraviolet light absorption, or the infra-red analyser which could be used for a number of different materials. These instruments are capable of giving a written record of atmospheric concentrations over a long period of time and can be designed to give an automatic warning if safe limits are exceeded, but their use in occupational hygiene is limited.

Dr. B. M. Wright, of the Pneumoconiosis Research Unit, presented a paper entitled "The Measurement of Dust Exposure for the Control of Pneumoconiosis", in which he said that it is essential to study both the incidence and severity of pneumoconiosis and the level of exposure to dust. The former is affected by the duration of the exposure and the concentration and composition of the dust. Once a relationship is established, then the safe limit will depend on what incidence and severity of pneumoconiosis is considered permissible. To make such studies possible, it is essential that general agreement should be reached on the methods of making the measure. ments, and then these methods will have to be applied on a wide scale.

The only instrument in common use that enables an estimate to be made of the concentration of respirable dust (between 5 and $I \mu$ in size) is the thermal precipitator. This collects the dust without breaking up aggregates but, owing to its comparatively short sampling period, its use becomes exceedingly laborious when long-term exposures are to be determined. The essential requirements of a suitable sampling instrument are : to enable an estimate to be made of the concentration and composition of airborne dust particles and aggregates in the respirable size-range; to yield a sample which can be assessed reasonably easily and accurately; to be capable of integrating its exposure over at least one working week; and to be cheap, robust, light, portable, self-contained and automatic. Until such an instrument has been produced and used over a period of many years, safe limits of dust exposure cannot be established with any precision. After his lecture, Dr. Wright displayed several new pieces of sampling apparatus, including a double aspirator for the thermal precipitator, an automatic sedimentation cell, and a selective mass-sampler. $\mathrm{H}_{\theta}$ said he hoped that the latter two instruments would make it possible to assess the level of exposure more accurately and less laboriously than has been possible hitherto.
Dr. W. G. Marley, head of the Division of Health Physics, Atomic Energy Research Establishment, Harwell, read a paper on "Permissible Levels of Exposure to Ionizing Radiations and Radioactive Materials". At the beginning of his paper he said that, with the introduction of a wide range of isotopes and the ever-increasing use of equipment emitting $\mathrm{X}$-rays and gamma-rays, it has become necessary to re-examine early information on permissible levels of exposure and to extend their applicability. At the 1953 meeting of the International Congress of Radiology, the International Commission on Radiological Protection drew up a list of recommended values for the maximum permissible body burden of a wide range of isotopes, and of the corresponding levels in air and drinking-water. This is soon to be published. Dr. Marley discussed the derivation of some of these recommended values. From prolonged and wide experience of X-rays and gamma-rays, it has been possible to arrive at a basic tolerance of $0.3 \mathrm{r}$. $/$ week in the tissue, which corresponds in certain circumstances to approximately $0.5 \mathrm{r}$. $/$ week measured with back-scatter on the surface of the body. Experience of radium ingestion by radium dial painters has enabled another basic tolerance to be set, namely, $0 \cdot 1 \mu \mathrm{gm}$. radium fixed in the skeleton, and this is thought to be safe over a working lifetime.

By making allowance for the 'relative biological effectiveness' of the different types of radiation or isotopes, it has been possible to determine permissible levels of exposure to a wide range of substances. The 'relative biological effectiveness' is usually determined from animal experiments, but there is also a limited experience arising from accidental exposure of men. Parameters that affect the ealculation of permissible levels include the fractional uptake from lungs or gut, the metabolism of the element, the organ of concentration, the biological half-life and the overall relative toxicity. The recommended levels are based on occupational exposures, when only a small fraction of the population are exposed. Dr. Marley stressed that, should an appreciable part of the whole inbreeding population be exposed, then genetic effects would have to be considered. He also discussed the effects of exposure, either by accident or in an emergency, to much more intense radiation for short periods.

R. J. SHERWOOD

\section{DISTRIBUTION MAPS OF THE BRITISH FLORA}

$T$

HE British Isles are probably as well known botanically as anywhere on the earth's surface; the long unbroken tradition of field botany as a hobby, traceable from the seventeenth century, has resulted in the accumulation of a mass of information on the occurrence of higher plant species, much of which has been systematized during the past hundred years on the 'vice-county' recording system due to H. C. Watson. This system, which constituted an important advance in the recording of plant distribution at the time of its inception in 1852, has naturally revealed inadequacies since that time, and at a conference in 1950 the Botanical Society of the British Isles reviewed the whole question of aims and methods in the study of distribution of British plants, in the light of the requirements of modern botanical research. At this conference recent methods of mapping in use in other countries were discussed, 